\title{
DISPUTAS POR NOMES E MARCAS EMPRESARIAIS: O RACIOCÍNIO DO SUPERIOR TRIBUNAL DE JUSTIÇA NO HARD CASE "ODEBRECHT" COMO UM EXEMPLO DO PENSAMENTO TIPOLÓGICO DE KARL LARENZ
}

\author{
Daniel Oitaven Pearce Pamponet Miguel \\ Alessandra Oitaven Pearce de Carvalho Monteiro ${ }^{* *}$
}

\begin{abstract}
Resumo
Este artigo tem como objetivo geral analisar a decisão do STJ sobre nomes e marcas empresariais no hard case "Odebrecht". A pesquisa é teórica, é qualitativa, utiliza o procedimento metodológico da análise de conteúdo bibliográfico e assume como referencial teórico a noção de pensamento tipológico de Larenz. A investigação justifica-se pelo fato de aquele caso ilustrar dilemas enfrentados pelos intérpretes do direito privado ao atribuírem predicados indeterminados aos nomes e marcas empresariais. Concluiu-se que noções tipológicas (novidade, veracidade, territorialidade, especificidade) sofreram, mediante argumentos sistemáticos e teleológicos, diversos deslocamentos de sentido em função da ponderação contextual de fatos realizada pelo STJ.
\end{abstract}

Palavras-chave: hard case "Odebrecht"; hermenêutica no direito privado; disputas por nomes empresariais; disputas por marcas empresariais; raciocínio tipológico

\section{TRADE NAME AND BUSINESS NAME DISPUTES: BRAZILIAN'S SUPERIOR COURT OF JUSTICE'S LARENZ-INSPIRED TYPOLOGICAL LEGAL REASONING IN THE "ODEBRECHT" HARD CASE}

\begin{abstract}
This article aims to assess a decision by Brazilian's Superior Court of Justice about a trade name and business name dispute: the "Odebrecht Hard Case". This theoretical and qualitative research uses bibliographic content analysis as a methodological procedure. The core of its theoretical framework is Larenz's typological thinking. Its relevance stems from that case being an example of the interpretive dilemmas lawyers face when assessing if trade or business names display a given attribute. We concluded that the court's contextual balancing of facts based on systemic and teleological arguments continuously shifted the meaning of types such as "novelty" and "territoriality".
\end{abstract}

\footnotetext{
* Doutor em Direito (UFBa). Doutor em Ciências Sociais (UFBa). Mestre em Direito (UFBA). Especialista em Filosofia do Direito (PUC-MG). Fraduado em Direito (UFBa). Ex-professor efetivo de Direito Civil da Universidade Estadual da Bahia (UNEB). Ex-professor substituto de Direito Empresarial e Direito Civil da UFBa. Professor adjunto (efetivo) de "Hermenêutica", "Argumentação", "Instituições de Direito Público e Privado" e "Teoria do Direito" da graduação em Direito da UFBa. Professor permanente do Programa de Pósgraduação stricto sensu (Mestrado e Doutorado) em Direito da UFBa. Prof. da Faculdade Baiana de Direito. Advogado. Sócio do "Oitaven \& Pearce" (consultoria e litigância em hard cases).

** Doutoranda em Ciências Jurídico-Filosóficas (Universidade de Coimbra, Portugal). Doutoranda em Análise Econômica do Direito (UFBA). Mestre em Direito Constitucional (Universidade de Coimbra, Portugal). Pósgraduada em Direito Tributário (UNIFOR). Ex-professora substituta da Universidade Federal da Bahia. Advogada. Sócia do "Oitaven \& Pearce" (consultoria e litigância em hard cases).
} 
Keywords: "Odebrecht" hard case; legal reasoning in private law; trade name disputes; business name disputes; typological thinking

\section{INTRODUÇÃO}

Este artigo tem como objetivo geral analisar a aplicação pelo Superior Tribunal de Justiça dos critérios jurídicos de resolução de conflitos referentes ao reconhecimento exclusivo dos direitos sobre nomes empresariais semelhantes (doravante, "conflitos nome/nome"), marcas empresariais semelhantes (daqui em diante, "conflitos marca/marca") e um nome e uma marca semelhantes (ao longo do texto, "conflitos nome/marca") no hard case "Odebrecht.

A investigação ora realizada consiste em pesquisa teórica, qualitativa, que utiliza o procedimento metodológico da análise de conteúdo bibliográfico e que assume como referencial teórico a noção de pensamento tipológico de Karl Larenz (2005), segundo a qual a qualificação jurídica de eventos reais pressupõe uma atribuição valorativa de sentido a textos indeterminados ${ }^{1} \mathrm{e}$, consequentemente, a identificação de traços meramente eventuais (ou seja, que não estarão necessariamente presentes em outros casos regidos pela mesma disposição normativa) nesses eventos.

Entendido o direito como práxis, nos moldes da tradição aristotélica do termo, a utilização de um hard case (problema jurídico que carece de respostas facilmente identificáveis nas principais fontes do direito, como a Constituição, as leis, os regulamentos, os enunciados sumulares e os precedentes vinculantes) como eixo metodológico contribui para o treinamento do raciocínio jurídico tipológico no campo da atividade empresarial ${ }^{2}$.

\footnotetext{
${ }^{1}$ A indeterminação textual no âmbito do direito privado é discutida no Brasil, exemplificativamente, por autores como Rodney Malveira da Silva (2011, p. 255 e ss.) e Judith Martins-Costa (2015, p. 141 e ss.). A complexidade interpretativa de textos tipológicos costuma ser abordada no Brasil mediante o uso de terminologia mais consolidada em nossa tradição jurídica, na qual se costuma usar a expressão "conceitos jurídicos indeterminados".

${ }^{2}$ Hart (2001, p. 314) descreve um hard case como um caso controverso, ou seja, um caso para o qual qual juristas razoáveis devidamente informados podem oferecer respostas conflitantes. Por sua vez, Dworkin (2002, p. 164-5) descreve da seguinte maneira o que costumeiramente é entendido como um hard case: "Nos casos difíceis, a argumentação jurídica versa sobre os conceitos contestados, cuja função e natureza são muito semelhantes ao conceito das características de um jogo. Eles incluem muitos dos conceitos substantivos através dos quais o direito se manifesta, como os conceitos de contrato e propriedade. Também se incluem aí dois conceitos de muito maior relevância para a presente argumentação. O primeiro é a ideia de "intenção" ou "propósito" de uma determinada lei ou de uma cláusula estabelecida por lei. Este conceito faz uma ponte entre a justificação política da ideia geral de que as leis criam os direitos e aqueles casos difíceis que interrogam sobre que direitos foram criados por uma lei específica. O segundo é o conceito de princípios vinculados às regras
} 
Assumiremos, pois, como expediente metodológico, um estudo da mencionada decisão proferida pelo STJ.

A investigação, como aprofundamento de trabalho anteriormente desenvolvido sobre a matéria, justifica-se também pelo caráter ilustrativo do conflito em questão para o estudo dos dilemas enfrentados pelos intérpretes do direito privado no que diz respeito à atribuição de predicados indeterminados aos nomes empresariais (como "veracidade") e marcas empresariais (como "especificidade/novidade relativa"). Ademais, a despeito da existência de alguns (poucos) trabalhos teóricos sobre o caso na produção jurídica nacional (MIGUEL, 2020; VERAS, 2020; SANTIAGO, 2020), nenhum deles apresenta um referencial teórico consistente em matéria de hermenêutica jurídica no âmbito do direito privado, visto que seus conteúdos se resumem a comentários de base meramente doutrinária sobre o caso. Essa é justamente a lacuna teórica que este artigo se presta a preencher.

O problema de pesquisa pode ser formulado da seguinte maneira: o STJ desenvolveu um raciocínio tipológico adequado ao resolver o conflito envolvendo nome empresarial e marca empresarial no hard case "Odebrecht"?

Os objetivos específicos do escrito são:

1) Avaliar o modo como o Superior Tribunal de Justiça, para solucionar o conflito entre nomes empresariais, adotou uma compreensão sistemática do princípio da novidade, segundo a qual, em função da aplicação concorrente do princípio da veracidade, a novidade deve ser compreendida à luz do cotejo entre o nome globalmente considerado e a finalidade normativa de obstar a confusão no mercado;

2) Analisar a conclusão do STJ de que nenhuma das marcas em conflito é de alto renome

3) Apreciar o posicionamento do STJ sobre o caráter patronímico da palavra “Odebrecht” em relação às duas sociedades empresárias envolvidas

4) Analisar o modo como o STJ considerou o critério de especificidade aplicável para resolver conflitos marca/marca e nome/marca

positivas do direito, ou que nelas estão 'inscritos'. Este conceito faz uma ponte entre a justificação política da doutrina segundo a qual os casos semelhantes devem ser decididos da mesma maneira e aqueles casos difíceis nos quais não fica claro o que essa doutrina geral requer." 
Antes de adentrarmos propriamente a análise do hard case, apresentaremos, em tópico próprio, as bases do pensamento tipológico de Karl Larenz, cerne do referencial teórico adotado por este escrito.

\section{O PENSAMENTO TIPOLÓGICO DE KARL LARENZ}

A visão sobre a Ciência do Direito proposta por Karl Larenz (2005) manifesta-se na forma de um pensamento racional orientado a valores, o qual, segundo o autor, assume o que ele chamada de método científico-espiritual. O autor entende que mesmo quando todas as notas distintivas do conceito são identificáveis em uma dada situação de fato, tal operação, ainda que seja supostamente lógica, pressupõe uma atividade mediadora por parte do interprete, a qual é inexoravelmente valorativa. Tal concepção está diretamente relacionada à distinção realizada pelo autor entre conceito e tipo, fundamental para a linha de raciocínio desenvolvida neste trabalho.

Na concepção de Larenz (2005, p. 655), pode-se falar em um conceito jurídico quando todas as notas distintivas de uma dada noção jurídica prevista na legislação estão presentes em todos os objetos que nela se encaixam. No contexto de um silogismo de subsunção, a definição do conceito figura como premissa maior; a constatação, mediada pela percepção, de que o objeto apresenta todas as notas distintivas mencionadas na definição funciona como premissa menor; e a afirmação de que um dado objeto é um caso do gênero designado por meio do conceito consiste na conclusão. De tal maneira, o legislador precisaria ser o mais preciso possível ao estabelecer os elementos de um conceito, de modo que a situação de fato a ele pudesse ser enquadrada subsuntivamente, sem que fosse necessário recorrer a pontos de vista valorativos.

Segundo Larenz (2005, p. 656), se, por um lado, a subsunção teria a vantagem de livrar o aplicador da lei do incômodo de realizar uma aplicação valorativa e, consequentemente, dos riscos à segurança jurídica que esta traria, por outro, é deveras raro que um dispositivo legal possa ser aplicado de modo subsuntivo em sentido estrito. Ademais, como o autor percebe, o modelo conceitual tem a desvantagem de os elementos de um conceito, frequentemente, abarcarem casos aos quais a ratio legis do dispositivo não é adequável, ou, ao contrário, não englobar todos os casos que devem ser regidos por aquela ratio legis. Por tais razões, no contexto de um pensamento orientado a valores como o de 
Larenz, a dogmática reconhece não ser possível apreender todos os fenômenos em conceitos, como queria uma noção cientificista de ciência, nem traduzir as conexões axiológicas do sistema interno de princípios jurídico-positivos em conceitos lógico-jurídicos organizados em um sistema externo de caráter puramente formal. O pensamento jurídico-dogmático também é orientado à atividade prática e, por isso, é diretamente orientado a valores, como se pode verificar pela crescente análise tipológica e interpretativo-teleológica das normas jurídicas pelos cientistas do direito.

O tipo é, por excelência, a forma de pensamento a ser utilizada quando os conceitos lógico-abstratos e seus respectivos sistemas lógicos não são adequados para a compreensão de um fenômeno da vida ou de uma conexão de sentido na multiplicidade de suas manifestações. Sua aplicabilidade já foi verificada em outras ciências que não o Direito. Nas Ciências Sociais, por exemplo, Max Weber (2009) celebrizou a ideia de "tipo ideal", enquanto Jellinek (2002) utilizou os tipos no campo da Teoria Geral do Estado. Larenz registra que até mesmo na Psicologia, na Linguística e na História o uso dos tipos é usual.

O pensamento tipológico, segundo Larenz (2005, p. 307), consiste em identificar se "as notas características tidas como típicas estão presentes em grau e intensidade suficientes para que a situação de fato no seu todo corresponda à imagem fenomênica do tipo". A despeito de todas as concepções modernas de tipo e suas particularidades, inclusive quando comparadas à ideia de conceito, algo está sempre presente: uma maior concretude do tipo em relação ao conceito. Ora, um tipo apresenta certas propriedades idôneas a configurar uma imagem em sua globalidade, ainda que nem sempre todos esses traços estejam presentes em cada exemplar e que sua intensidade seja variável em cada fato que a ele se reconduz. Enquanto o pensamento de abstração conceitual busca sempre enquadrar conceitos menos gerais em conceitos mais gerais por meio de um processo de encaixe das notas características em comum e de descarte das notas diferentes entre os níveis de categorias, o pensamento tipológico mantém unidas as notas distintivas do tipo e serve-se delas unicamente para descrever o tipo como uma nota distintiva do todo. Este expediente permite a conservação, no plano da apreensão intelectual, da imagem global intuída, motivo pelo qual se justificam as afirmações de que o tipo está situado entre, de um lado, o individual e concreto, e, de outro, o conceito abstrato. 
O jusfilósofo alemão atrela ao pensamento tipológico a noção de que o legislador, ao inserir um tipo no texto normativo, assume um ponto de vista valorativo retor, o qual orienta a determinação de consequências jurídicas positivada, de modo que o tipo, visto como um quadro global, encontra fundamento na própria ratio legis. O juiz e o cientista do direito, ao fazerem uma coordenação do caso ao tipo, estabelecem se os seus indícios típicos justificam, pelo seu grau de intensidade e articulação, a caracterização concreta do tipo, o qual pode ser formado por alguns elementos imprescindíveis somados a outros traços variáveis. Aqui, faz-se pertinente a menção de Larenz (2005, p. 670 e ss.) à ideia de sistema móvel, ou seja, um sistema composto por elementos dotados de uma força variável diante de cada situação aplicativa. Essa variação admite também que, em certas circunstâncias, alguns dos elementos nem estejam presentes e, eventualmente, sejam substituidos por outros. Karl Larenz estabelece, então, uma analogia entre a figura do sistema móvel e o jogo concertado de diferentes princípios em distintos graus de concretização tipológica orientada a valores com suporte na organização de grupos de casos representativos reconduzíveis aos tipos previstos no sistema. Portanto, nesse contexto, o caráter sistemático não se esvai justamente porque a mobilidade do sistema torna evidente a unidade em sua pluralidade.

Vejamos, nas palavras do próprio Larenz (2005, p. 403-4), um exemplo de raciocínio tipológico:

Segundo o § 950 do BGB «quem, por meio de elaboração ou transformação de um ou vários materiais, fabrica uma coisa móvel nova», adquire a propriedade da coisa nova «sempre que o valor da elaboração ou transformação não seja manifestamente inferior ao valor dos materiais». [...] a questão relativa a saber quando se trata de uma coisa «nova». $\mathrm{O}$ aluno $\mathrm{A}$ talhou e construiu uma caixinha [...] a partir de uma tábua que não the pertencia. Ninguém porá em dúvida [...] que se trata de uma coisa «nova». Modifiquemos a situação: A desmontou uma caixinha feita rudimentarmente de madeira não trabalhada, adornou os tampos da caixinha mediante um entalhamento primoroso e voltou a armá-lo. A caixinha agora ainda é a mesma, só modificada no aspecto exterior e no seu valor, ou é uma coisa «nova»? [...] Se se procura sabê-lo por meio de uma definição conceptual, para tornar possível uma subsunção, [...] dificilmente se poderá achar um critério que se ajuste em todos os casos à intenção da lei. A modificação da forma e aspecto pode ser um indício, mas não é nem necessária, nem [...] suficiente, para considerar «nova» a coisa modificada. [...] Pode-se dizer que a caixinha, primorosamente entalhada, é, antes como depois, uma caixinha, e assim, a mesma coisa, ou é agora uma «obra de arte» [...] e, por conseguinte uma «coisa nova»? Ou deve-se sublinhar a distinta utilidade da coisa actual, [...] o distinto fim de uso? O legislador quis [...] conferir prevalência à atividade criadora de valor, face à mera propriedade dos materiais. Isto dá a entender um «modo de consideração econômico» que se centra no facto de 
se, mediante a elaboração ou transformação, foi criado um valor que não é despiciendo em relação com o valor dos materiais. Isto pode acontecer também com a reparação total, com a qual, segundo a opinião geral, não se produz uma «coisa nova». A coisa reparada é somente reposta no seu estado anterior; torna-se de novo idônea para a finalidade de uso originária.

O exemplo de Larenz refere-se ao modo de aquisição da propriedade designado como "especificação", cuja regulação no direito civil brasileiro é razoavelmente semelhante à da legislação alemã mencionada por Larenz, como se pode depreender do art. 1269, caput e par. $2^{\circ}$, do Código Civil ${ }^{3}$. Essencial na lição do autor é compreender que não há um critério único para a caracterização da coisa como "nova", e sim uma conjugação de critérios cujos pesos variam de acordo com a especificidade do caso. Larenz (2005, p. 405) chama o juízo baseado nessa pluralidade de critérios de "ponderação de fatos" e explica que, no contexto do exemplo da caixinha, a decisão sobre atribuir ou não o predicado "nova" ao objeto não resulta de uma mera constatação de fatos baseada na percepção, e sim de uma apreciação valorativa regida pela disposição normativa correlata.

\section{APRESENTAÇÃO dOS CONTORNOS GERAIS E PRINCIPAIS PONTOS DE CONFLITO DO HARD CASE "ODEBRECHT"}

A Odebrecht S/A, sociedade empresária cujos atos constitutivos estão arquivados na Junta Comercial do Estado da Bahia, postulou contra a Odebrecht Comércio e Indústria de Café Ltda., cujo registro foi realizado na Junta Comercial do Estado do Paraná, e contra o Instituto Nacional de Propriedade Industrial (INPI) o reconhecimento exclusivo do uso empresarial do termo "Odebrecht" e a declaração de nulidade do registro da marca “Odebrecht” pela sociedade empresária paranaense.

Devemos notar, de pronto, que a sociedade empresária baiana aduziu a existência de três tipos de ofensa diferentes por parte da pessoa jurídica paranaense. A primeira delas diria respeito a suposto descumprimento do art. 8 da Convenção da União de Paris, resultando em dano ao seu direito de exclusividade quanto ao exercício do nome empresarial,

\footnotetext{
3"Art. 1.269. Aquele que, trabalhando em matéria-prima em parte alheia, obtiver espécie nova, desta será proprietário, se não se puder restituir à forma anterior. [...]. § $2 \stackrel{\circ}{-}$ Em qualquer caso, inclusive o da pintura em relação à tela, da escultura, escritura e outro qualquer trabalho gráfico em relação à matéria-prima, a espécie nova será do especificador, se o seu valor exceder consideravelmente o da matéria-prima.
} 
independentemente da classe de atividade respectiva - nesse particular, portanto, haveria de um conflito entre nomes empresariais. A segunda ofensa seria referente ao registro de "Odebrecht" como marca da sociedade paranaense, o que configuraria um desrespeito ao nome empresarial da pessoa jurídica baiana - em outros termos, existiria um conflito entre um nome empresarial e uma marca. A terceira e última ofensa consistiria na prática de concorrência desleal, visto que o registro da marca "Odebrecht" pela pessoa jurídica paranaense desrespeitaria a exclusividade da pessoa ideal baiana no uso de tal marca teríamos, então, um conflito entre marcas.

As principais teses jurídicas adotadas pelo STJ (BRASIL, REL. MIN. JORGE SCARTEZZINI, 2020) ao decidir a matéria foram devidamente sintetizadas na ementa do acórdão respectivo, como se pode deprender do seguinte excerto:

4. A proteção legal da denominação de sociedades empresárias, consistente na proibição de registro de nomes iguais ou análogos a outros anteriormente inscritos, restringe-se ao território do Estado em que localizada a Junta Comercial encarregada do arquivamento dos atos constitutivos da pessoa jurídica.

5. Não se há falar em extensão da proteção legal conferida às denominações de sociedades empresárias nacionais a todo o território pátrio, com fulcro na Convenção da União de Paris, porquanto, conforme interpretação sistemática, nos moldes da lei nacional, mesmo a tutela do nome comercial estrangeiro somente ocorre em âmbito nacional mediante registro complementar nas Juntas Comerciais de todos os Estados-membros.

6. A análise da identidade ou semelhança entre duas ou mais denominações integradas por nomes civis (patronímicos) e expressões de fantasia comuns deve considerar a composição total do nome, a fim de averiguar a presença de elementos diferenciais suficientes a torná-lo inconfundível.

7. A proteção de denominação social e nome civil em face do registro posterior de marca idêntica ou semelhante encontra previsão dentre as vedações legais previstas ao registro marcário (art. 65, V e XII, da Lei $\mathrm{n}^{\circ}$ 5.772/71, aplicável, in casu).

8. Conquanto objetivando tais proibições a proteção de nomes comerciais ou civis, mencionada tutela encontra-se prevista como tópico da legislação marcária, pelo que o exame de eventual colidência não pode ser dirimido exclusivamente com base no critério da anterioridade, subordinando-se, em atenção à interpretação sistemática, aos preceitos legais condizentes à reprodução ou imitação de marcas, é dizer, aos arts. 59 e 65, XVII, da Lei ${ }^{\circ}$ 5.772/71, consagradores do princípio da especificidade.

9. Especificamente no que tange à utilização de nome civil (patronímico) como marca, verifica-se a absoluta desnecessidade de autorização recíproca 
entre homônimos, além da inviabilidade de exigência, ante a ausência de previsão legal, de sinais distintivos à marca do homônimo que proceder posteriormente ao registro, também submetendo-se eventual conflito ao princípio da especificidade.

10. Consoante o princípio da especificidade, o INPI agrupa os produtos ou serviços em classes e itens, segundo o critério da afinidade, de modo que a tutela da marca registrada é limitada aos produtos e serviços da mesma classe e do mesmo item. Outrossim, sendo tal princípio corolário da necessidade de se evitar erro, dúvida ou confusão entre os usuários de determinados produtos ou serviços, admite-se a extensão da análise quanto à imitação ou à reprodução de marca alheia ao ramo de atividade desenvolvida pelos respectivos titulares.

11. À caracterização de "marca notória" (art. 67, caput, da Lei $n^{\circ}$ 5.772/71), a gozar de tutela especial impeditiva do registro de marcas idênticas ou semelhantes em todas as demais classes e itens, perfaz-se imprescindível a declaração de notoriedade pelo INPI, com a concessão do registro em aludida categoria especial.

12. Diversas as classes de registro e o âmbito das atividades desempenhadas pela embargante (comércio e beneficiamento de café, milho, arroz, cereais, frutas, verduras e legumes, e exportação de café) e pela embargada (arquitetura, engenharia, geofísica, química, petroquímica, prospecção e perfuração de petróleo), e não se cogitando da configuração de marca notória, não se vislumbra impedimento ao uso, pela embargante, da marca Odebrecht como designativa de seus serviços, afastando-se qualquer afronta, seja à denominação social, seja às marcas da embargada. Precedentes.

13. Possibilidade de confusão ao público consumidor dos produtos e serviços das litigantes expressamente afastada pelas instâncias ordinárias, com base no exame do contexto fático-probatório, do qual são absolutamente soberanas.

Analisaremos, ao longo do texto, todas essas teses, fazendo referência a elas de acordo com a numeração utilizada pelo próprio tribunal - exemplificativamente, a tese de que "a proteção legal da denominação de sociedades empresárias, consistente...” será designada, para fins de simplificação como tese (4).

Uma compreensão adequada dos elementos conflituosos envolvidos no problema ora analisado exige que diferenciemos preliminarmente: de um lado, a noção de marca, compreendida como o termo que especifica os produtos ou serviços oferecidos pelo exercente de atividade empresarial; e, de outro, o nome empresarial, entendido como a identificação da sociedade empresária e protegido, mutatis mutandis, nos mesmos moldes que as disposições legais sobre direitos da personalidade preservam o nome da pessoa natural. A proteção do 
nome empresarial é circunscrita ao âmbito estadual, enquanto a proteção à marca é de caráter federal. Tal distinção se reflete na determinação legal das entidades responsáveis por realizar o registro de tais categorias: o registro do nome empresarial deve ser arquivado na junta comercial da unidade federativa respectiva, enquanto a marca deve ser registrada no INPI, autarquia federal.

Alguns dos elementos fundamentais decisivos para a análise dos conflitos nome/nome, nome/marca e marca/marca são: (1) a aplicação dos princípios da veracidade, da unicidade e da novidade aos conflitos entre nomes empresariais; (2) a qualificação de marca de alto renome nos conflitos nome-marca e marca-marca; (3) relevância da adoção de patronímico de fundador como elemento componente do nome (conflitos nome/marca) ou como marca (conflitos marca/marca); e (4) a aplicação do princípio da especificidade nos conflitos nome/marca e marca/marca. Não surpreende, pois, que todas essas noções tenham sido abordadas pelos ministros do STJ ao decidirem o hard case "Odebrecht".

Expostos os contornos gerais da lide, podemos analisar propriamente as teses jurídicas assumidas pelo STJ na resolução dos conflitos referentes às matérias de nome empresarial e marca empresarial englobados pelo hard case "Odebrecht".

\section{ANÁLISE CRÍTICA DAS TESES JURÍDICAS DO SUPERIOR TRIBUNAL DE JUSTIÇA NA DECISÃO DO HARD CASE "ODEBRECHT"}

O STJ, conforme a mencionada tese (4), entende que a proteção ao nome empresarial se restringe à unidade federativa compreendida pela junta comercial em que o registro da sociedade empresária está arquivado. Nesse ponto, devemos lembrar que a Odebrecht S/A postulou a aplicação do art. 8 da Convenção da União de Paris, o qual determinaria que todos os países compreendidos por tal União deveriam proteger o nome empresarial em toda a esfera territorial, independentemente de depósito ou registro, em todo o território pátrio ${ }^{4} \mathrm{O}$ tribunal enfrentou tal argumento com base em uma interpretação sistemática da referida convenção ${ }^{5}$. O art. 20 da referida fonte normativa dispõe que a tutela do nome empresarial

\footnotetext{
4 "Artigo 8. O nome comercial será protegido em todos os países da União sem obrigação de depósito ou de registro, quer faça ou não parte de uma marca de fábrica ou de comércio."

${ }^{5}$ Sobre a interpretação sistemática e sua conexão com a interpretação teleológica, Larenz (2005, p. 458-62) discorre da seguinte maneira: "O contexto significativo da lei determina, em primeiro lugar, da mesma maneira, a compreensão de cada uma das frases e palavras, tal como também, aliás, a compreensão de uma passagem do texto é codeterminada pelo contexto. [...] não se trata mais do que da forma mais simples do [...] «círculo
} 
estrangeiro está submetida aos ditames da lei nacional, de modo equiparado às exigências feitas aos nacionais para a obtenção de tal proteção ${ }^{6}$. Isso significa, segundo o STJ, que o nome comercial estrangeiro, assim como o nome comercial de sociedade empresária nacional, só encontra proteção em todo o território brasileiro nos casos de registro em todas as juntas comerciais do país, conforme consolidado na tese (5).

No caso em questão, a sociedade do ramo de construção civil está registrada na Bahia, enquanto a pessoa jurídica exercente de atividade empresarial no ramo alimentício tem seu registro arquivado no Paraná, o que significa que o uso exclusivo de suas denominações está restrito, respectivamente, a esses estados-membros, não se configurando, portanto, o suposto conflito entre nomes empresariais suscitado pela Odebrecht S/A. A extensão de tal proteção para os demais estados exigiria o registro em cada um dos estados-membros em que se pretendesse a exclusividade, sendo este o único caminho para que o nome fosse protegido em todo o país - salvo, obviamente, em hipótese de reconhecimento de marca notória.

Podemos concluir, então, que, caso a sociedade empresária baiana houvesse registrado seu nome empresarial na junta comercial paranaense anteriormente à prática do ato respectivo pela Odebrecht Comércio e Indústria de Café Ltda., esta estaria impedida de fazêlo? Segundo o STJ, uma interpretação do caso à luz dos princípios que orientam a formação do nome empresarial - matéria regulada, à época do registro do nome da sociedade empresária atualmente chamada de "Odebrecht S/A", pelos art. 105, 106 e 108 do Decreto-lei

hermenêutico». Uma lei é constituída, [...] as mais das vezes, por proposições jurídicas incompletas [...], que só conjuntamente com outras normas se complementam numa norma jurídica completa ou se associam numa regulação. O sentido de cada proposição jurídica só se infere, as mais das vezes, quando se a considera como parte da regulação a que pertence. [...] o contexto significativo da lei desempenha um amplo papel em ordem à sua interpretação, ao poder admitir-se uma concordância objectiva entre as disposições legais singulares. Entre várias interpretações possíveis segundo o sentido literal, deve por isso ter prevalência aquela que possibilita a garantia de concordância material com outra disposição. [...] A conexão de significado da lei, e também a sistemática conceptual [...] só é compreensível quando se tomam também em consideração os fins da regulação. [...]. A conexão de significado da lei [...] só pode plenamente compreender-se, em muitos casos, quando se retorna à teleologia da lei."

6 "Art. $2^{\circ}$. 1) Os nacionais de cada um dos países da União gozarão em todos os outros países da União, no que se refere à proteção da propriedade industrial, das vantagens que as leis respectivas concedem atualmente ou venham a conceder no futuro aos nacionais, sem prejuízo dos direitos especialmente previstos na presente Convenção. Em consequência, terão a mesma proteção que estes e os mesmos recursos legais contra qualquer atentado dos seus direitos, desde que observem as condições e formalidades impostas aos nacionais. 2) Nenhuma condição de domicilio ou de estabelecimento no país em que a proteção é requerida pode, porém, ser exigida dos nacionais de países da União para o gozo de qualquer dos direitos de propriedade industrial. 3) Ressalvam-se expressamente as disposições da legislação de cada um dos países da União relativas ao processo judicial e administrativo e à competência, bem como à escolha de domicílio ou à designação de mandatário, eventualmente exigida pelas leis de propriedade industrial." 
$7903 / 45^{7} 8$ - quais sejam, o da veracidade (a denominação deve espelhar a atividade verdadeiramente exercida pelo empresário), o da unicidade (utilização de uma única denominação nas relações negociais) e o da novidade ou originalidade (as denominações não devem se confundir com outras já registradas pela mesma junta comercial, de modo a evitar confusão naquele espaço geográfico), não existiria tal impedimento. Senão, vejamos.

Ainda que o princípio da novidade obste a existência de homonímia ou semelhança geradora de confusão na área do estado-membro e seja densificado, legislativamente, por meio do critério da anterioridade do registro (art. 108 do Decreto-lei 7903/45), a falta de um critério legal para a determinação do que é uma denominação idêntica ou semelhante levou boa parte da doutrina - por todos, Fabio Ulhoa Coelho $(2019$, p. 84) - a considerar que a composição total do nome deve ser tomada em conta na busca por elementos de diferenciação idôneos a evitar que os consumidores incorram em confusão, entendimento subscrito pelo STJ em sua tese (6). Ademais, o STJ considerou que os patronímicos idênticos foram acompanhados por termos que, em consonância com o princípio da veracidade, identificam os ramos de atividade contemplados pelas duas sociedades empresárias, as quais se desenvolvem em segmentos distintos, o que afasta a possibilidade de confusão pelos consumidores e, consequentemente, a hipótese de concorrência desleal ${ }^{9}$, em conformidade com as teses (12) e (13) do tribunal.

\footnotetext{
7 "Art. 105. Para que possa ser assegurado em todo o território nacional o direito ao uso exclusivo do nome comercial, deverá o interessado promover-lhe o registro, na forma aqui estabelecida."; "Art. 106. O registro da firma individual e o arquivamento ou inscrição dos contratos, atos constitutivos, estatutos ou compromissos das sociedades comerciais, industriais e agrícolas, ou das sociedades civis e fundação, efetuados no Departamento Nacional de Indústria e Comércio, nas Juntas Comerciais, ou nos ofícios que lhes forem privativos, assegurarão o uso exclusivo do nome somente nos limites do domić́lio do titular que houver efetuado aquêle registro. Parágrafo único. Toda firma ou denominação nova deverá se distinguir suficientemente de qualquer outra estabelecida no mesmo local"; "Art. 108. Verificando-se identidade de nomes comerciais com registro federal e local, prevalecerá o de registro anterior, devendo aquele que o adotou posteriormente aditar-lhe a indicação de sede do estabelecimento principal ou qualquer outra designação distintiva."

${ }^{8}$ Atualmente, a matéria é regulada pelo Código Civil em seu Art. 1.166, segundo o qual "a inscrição do empresário, ou dos atos constitutivos das pessoas jurídicas, ou as respectivas averbações, no registro próprio, asseguram o uso exclusivo do nome nos limites do respectivo Estado", e pela Lei 8934/94, em seu art. 34, segundo o qual " O nome empresarial obedecerá aos princípios da veracidade e da novidade."
}

${ }^{9}$ As disposições legais sobre concorrência desleal supostamente aplicáveis ao caso seriam as constantes do art. 178, III e parágrafo. único, do Decreto-lei 7903/45 ("Art. 178. Comete crime de concorrência desleal que: [...] III. emprega meio fraudulento para desviar em proveito próprio ou alheio, clientela de outrem: Parágrafo único. Fica ressalvado ao prejudicado o direito de haver perdas e danos em ressarcimento de prejuízo causados por outros atos de concorrência desleal não previstos neste artigo, tendentes a prejudicar a reputação ou os negócios 
O STJ também entendeu que as pessoas naturais têm o direito de usar o nome civil como elemento de seu nome empresarial, o que, considerando que ambas as pessoas jurídicas foram fundadas por indivíduos cujos nomes civis englobavam o patronímico "Odebrecht”, obstaria a utilização do princípio da novidade como fundamento para o pleito da sociedade empresária baiana. Nesse ponto, surge a seguinte questão: a identidade dos patronímicos dos fundadores é relevante no que diz respeito ao conflito entre nomes empresariais? Parece-nos que não, mesmo na hipótese em que o termo em comum não fosse oriundo dos nomes dos fundadores.

Devemos notar que caso um dos sócios da sociedade paranaense não tivesse "Odebrecht" como patronímico, a adoção de tal termo assumiria a função de elementofantasia da denominação. Ainda assim, a análise do nome como um todo, devido ao registro da distinção entre os segmentos de atividade respectivos, seria suficiente para evitar a confusão, não sendo, igualmente, cabível qualquer alegação de ofensa ao nome civil do fundador da sociedade empresária baiana, já que não haveria qualquer tipo de impedimento nem mesmo na esfera empresarial. Igualmente, caso os ramos de atividade fossem iguais, a utilização de termo em comum geraria confusão, o que impediria o registro do nome na mesma circunscrição pela sociedade que o fizesse posteriormente, ainda que o termo em comum fosse o patronímico de ambos os fundadores.

É essencial, entretanto, perceber que a irrelevância da circunstância de o termo em comum ser o patronímico de ambos os fundadores das pessoas ideais não se estende aos conflitos entre nome e marca e entre marcas. Senão, vejamos.

O STJ, de modo perspicaz, apresenta o posicionamento de João da Gama Cerqueira (1982, p. 1230), para quem, corretamente, o critério de avaliação da existência de confusão entre os consumidores não pode ser o mesmo em todas as situações potencialmente conflituosas. Segundo o autor, os conflitos entre nomes podem seguir padrões menos rigorosos, já que as sociedades, ainda que tenham nomes parecidos, têm condições de se tornar especificamente conhecidas por meio de outros elementos, inclusive a própria marca. A função precípua do nome empresarial não é identificar a sociedade perante o grande público,

alheios, a criar confusão entre estabelecimentos comerciais ou industriais ou entre os produtos e artigos postos no comércio"). Atualmente, a matéria é regulada pelo art. 195 da Lei 9279.96. 
mas sim a de individualizá-la no tocante às relações jurídicas a ela concernentes. Diferentemente, a marca presta-se propriamente a distinguir o produto ou serviço em relação à concorrência. Agrega-se a isso a maior liberdade do empresário para compor as marcas, a qual viabiliza a imposição de um padrão mais rigoroso quanto à sua distinção perante as demais marcas e, até mesmo, os demais nomes empresariais.

O raciocínio acima exposto importa na tese (8) do STJ, segundo a qual o pleito de proteção do nome empresarial da sociedade empresária baiana em relação ao registro da marca "Odebrecht" pela pessoa jurídica paranaense não pode ser resolvido meramente pelo critério de anterioridade do registro. Ora, como explica João da Gama Cerqueira (1982, p. 1233), os princípios que dizem respeito à reprodução e imitação de marcas também são aplicáveis no conflito entre nome e marca, seja no caso de registro pretérito do nome em relação à marca, seja na situação inversa. A estrutura de pensamento, qualificada pelo STJ como "integrativa", é a seguinte: como as normas de proteção ao nome em relação ao registro posterior de marcas eram veiculadas, à época do hard case "Odebrecht", pela Lei 5.772/71, os princípios referentes à disciplina marcária, tema central de tal diploma normativo, devem ser aplicados à tutela do nome empresarial, já que esta, naquela lei, figura como uma espécie de "intrusa" (a regulação geral do nome empresarial é matéria atinente ao tema do registro de empresas, atualmente disciplinada por diploma legislativo de 1994). São, por interpretação sistemática, aplicáveis ao conflito entre nome e marca, portanto, dois princípios básicos da disciplina das marcas, consolidados nos arts. 59, 65, XVII, e 67 da Lei $\mathrm{n}^{\circ} 5.772 / 71^{10}$ diploma vigente à época dos fatos e, portanto, aplicável ao hard case "Odebrecht": o da territorialidade (a proteção abrange todo o território nacional, ainda que o produto só seja explorado em um dado município ou região) e o da especificidade/novidade relativa (apenas os produtos idênticos ou análogos, concernentes ao mesmo ramo de atividade, são protegidos,

\footnotetext{
10 "Art. 59. Será garantida no território Nacional a propriedade da marca e o seu uso exclusivo àquele que obtiver o registro de acôrdo com o presente Código, para distinguir seus produtos, mercadorias ou serviços, de outros idênticos ou semelhantes, na classe correspondente à sua atividade."; "Art. 65. Não é registrável como marca: [...] 17) imitação bem como reprodução no todo, em parte, ou com acréscimo, de marca alheia registrada para distinguir produto, mercadoria ou serviço, idêntico, semelhante, relativo ou afim ao ramo de atividade, que possibilite êrro, dúvida ou confusão, salvo a tradução não explorada no Brasil."; "Art. 67. A marca considerada notória no Brasil, registrada nos têrmos e para os efeitos dêste Código, terá assegurada proteção especial, em tôdas as classes, mantido registro próprio para impedir o de outra que a reproduza ou imite, no todo ou em parte, desde que haja possibilidade de confusão quanto à origem dos produtos, mercadorias ou serviços, ou ainda prejuízo para a reputação da marca."
} 
salvo em caso de marca notória) ${ }^{11}$.

O STJ, conforme sua tese (10), considerou que o princípio decisivo para a resolução do conflito é o da especificidade. Em vez de dar prevalência ao critério da anterioridade, o tribunal superior, conforme sua tese (13), considerou que a impossibilidade de confusão entre os consumidores deveria ser assumida como decisiva para a resolução do problema. A aplicação sistemática do princípio da especificidade, portanto, tomaria em conta, conforme a tese (12) do STJ, que a sociedade empresária baiana registrou a marca no Instituto Nacional de Propriedade Industrial como referente a atividades do ramo de construção civil. Ora, o INPI assume o critério da afinidade para classificar as marcas, agrupando os produtos e serviços respectivos de acordo com a área de atuação. De tal modo, apenas os produtos e serviços da mesma classe e do mesmo item entram em colisão, salvo nos casos em que esteja envolvida uma marca notória - o que, segundo o STJ, não é o caso em questão, visto que nenhuma das duas sociedades empresárias obteve o reconhecimento de suas marcas como notórias pelo INPI, requisito que, segundo a tese (11) do tribunal, é indispensável à caracterização da figura regulada pelo art. 67, caput, da Lei 5772/71. Aliás, como explica Tomazette (2006, p.2), é justamente porque não há, in casu, marca notória que incide o princípio da especificidade, visto que as marcas notórias prevalecem sobre o nome ou a marca alheia, independentemente da especificidade do ramo de atuação - apenas para exemplificar, a criação de um sabonete "Subway" obviamente evoca no consumidor a qualidade e as características comumente reconhecidas pela população em relação à sociedade produtora do ramo alimentício.

\footnotetext{
${ }^{11}$ A matéria é atualmente regulada pelos arts. 129, 124, XIX, 125 e 126 da Lei 9279/96, a qual revogou a Lei 5.772/71, mas, conforme consolidado pelo STJ no acórdão ora analisado, não se aplica ao hard case Odebrecht": "Art. 129. A propriedade da marca adquire-se pelo registro validamente expedido, conforme as disposições desta Lei, sendo assegurado ao titular seu uso exclusivo em todo o território nacional, observado quanto às marcas coletivas e de certificação o disposto nos arts. 147 e $148 . \S^{\circ} 1^{\circ}$ Toda pessoa que, de boa fé, na data da prioridade ou depósito, usava no País, há pelo menos 6 (seis) meses, marca idêntica ou semelhante, para distinguir ou certificar produto ou serviço idêntico, semelhante ou afim, terá direito de precedência ao registro. § $2^{\circ} \mathrm{O}$ direito de precedência somente poderá ser cedido juntamente com o negócio da empresa, ou parte deste, que tenha direta relação com o uso da marca, por alienação ou arrendamento."; "Art. 124. Não são registráveis como marca: [...] XIX - reprodução ou imitação, no todo ou em parte, ainda que com acréscimo, de marca alheia registrada, para distinguir ou certificar produto ou serviço idêntico, semelhante ou afim, suscetível de causar confusão ou associação com marca alheia"; "Art. 125. À marca registrada no Brasil considerada de alto renome será assegurada proteção especial, em todos os ramos de atividade."; "Art. 126. A marca notoriamente conhecida em seu ramo de atividade nos termos do art. $6^{\circ}$ bis (I), da Convenção da União de Paris para Proteção da Propriedade Industrial, goza de proteção especial, independentemente de estar previamente depositada ou registrada no Brasil. § $1^{\circ} \mathrm{A}$ proteção de que trata este artigo aplica-se também às marcas de serviço. $\S 2^{\circ} \mathrm{O}$ INPI poderá indeferir de ofício pedido de registro de marca que reproduza ou imite, no todo ou em parte, marca notoriamente conhecida."
} 
No caso em questão, temos a pretensão de registro de marca supostamente desrespeitosa a um nome empresarial já registrado, questão regulada, à época, pelo art. 5o da Lei $5.772 / 71^{12}$. Devemos notar, entretanto, que a sociedade empresária baiana não apenas suscita que o uso da marca "Odebrecht" pela sociedade empresária paranense ofende o seu nome empresarial (art. 65, V, da Lei 5772/71) - questão resolvida pelo STJ por meio do princípio da especificidade, conforme a tese (7) do tribunal - mas também que desrespeita 0 nome civil de seu fundador ("nome civil de terceiro", nos termos do art. 65, XII, da mesma lei $\left.{ }^{13}\right)$. O STJ reconheceu, em sua tese (7), a existência de vedação legal ao registro de "nome civil de terceiro", mas considerou inexistente qualquer ofensa ao nome civil de terceiro, com o argumento de que ambos os fundadores têm o mesmo patronímico, o que, conforme a tese (9) do tribunal, impediria a configuração do nome empresarial da sociedade paranaense, bem como do nome civil de seu fundador, como "nomes alheios",

E se "Odebrecht" não fosse patronímico do fundador da "Odebrecht Comércio e Indústria de Café Ltda", mas apenas do fundador da "Odebrecht S/A"? Nesse caso, parecenos que a solução seria distinta daquela referente ao conflito entre nomes empresariais, nos moldes da lição já mencionada de João da Gama Cerqueira. Senão, vejamos.

A adoção de uma marca que se confunde com o elemento-base do nome empresarial de outra sociedade empresária, mormente na situação em que este elemento-base é inspirado no patronímico de seu fundador, pode gerar confusões perante o público. A relevância atribuída pela legislação ao patronímico reforça tal ratio, ao lembramos que a Lei de Sociedades Anônimas, em seu art. 3, par.1, destaca a possibilidade de que a denominação seja composta pelo nome de fundadores, acionistas ou pessoas que tenham contribuído de modo relevante para o êxito da empresa ${ }^{14}$. Isso significa que, mesmo no caso de sociedades de capital, o elemento pessoal pode ser elevado a um patamar simbólico distintivo da sociedade empresária, inclusive no que diz respeito a suas negociações não realizadas com o grande

\footnotetext{
12 "Art. 65. Não é registrável como marca: [...] 5) título de estabelecimento ou nome comercial". Atualmente, a matéria é regulada no art. 124, V, da Lei 9279/96: "Art. 124. Não são registráveis como marca: [...] V reprodução ou imitação de elemento característico ou diferenciador de título de estabelecimento ou nome de empresa de terceiros, suscetível de causar confusão ou associação com estes sinais distintivos."

13 "Art. 65. Não é registrável como marca: [...] 12) nome civil, ou pseudônimo notório, e efígie de terceiro, salvo com expresso consentimento do titular ou de seus sucessores diretos"

14 "Art. $3^{\circ} \mathrm{A}$ sociedade será designada por denominação acompanhada das expressões "companhia" ou "sociedade anônima", expressas por extenso ou abreviadamente mas vedada a utilização da primeira ao final. § $1^{\circ} \mathrm{O}$ nome do fundador, acionista, ou pessoa que por qualquer outro modo tenha concorrido para o êxito da empresa, poderá figurar na denominação."
} 
público. Ora, se, por um lado, a marca realiza a ponte entre o mercado de consumo e a sociedade empresária, por outro, em negociações de grande porte, o nome empresarial pode ser decisivo e, quiçá, preponderante, pelo próprio peso que a pessoa que inspirou a denominação pode ter no mercado de negócios.

Da mesma forma, no que diz respeito ao conflito entre marcas, a adoção de “Odebrecht" por sociedade não relacionada ao patronímico seria um indício de concorrência desleal, visto que poderia ser considerada como um indevido aproveitamento das qualidades positivas do fundador da sociedade ofendida - lembremos, contudo, que, de qualquer modo, o prévio registro da marca pelo INPI obstaria tal tipo de acusação. Ora, a boa reputação do fundador só poderia ser refletida na marca pela própria empresa idealizada por ele. Concluímos, portanto, que a aplicação do princípio da especificidade só é viável, in casu, porque ambas as sociedades foram fundadas por sujeitos dotados do patronímico “Odebrecht”. Não podemos afirmar categoricamente que a decisão do STJ tenha estabelecido posicionamento no mesmo sentido, visto não ter enfrentado diretamente a possibilidade de prejudicialidade entre as questões do patronímico e do princípio da especificidade. Entretanto, dada a assunção do pensamento de João da Gama Cerqueira pelo tribunal, tal parece ser a melhor compreensão sistemática sobre o julgado.

\section{CONCLUSÃO: O STF RACIOCINOU TIPOLOGICAMENTE AO JULGAR O HARD CASE "ODEBRECHT"}

Concluímos que a melhor reconstrução possível do percurso lógico do STJ para identificação dos critérios de resolução do hard case "Odebrecht" pode ser disposta nos seguintes termos:

(1) Quanto ao conflito entre os nomes empresariais, sua resolução se deu por meio de uma compreensão sistemática do princípio da novidade, o qual, em função da aplicação concorrente do princípio da veracidade, deve ser compreendido à luz do cotejo entre o nome globalmente considerado e a finalidade normativa de obstar a confusão no mercado;

(2) Quanto aos conflitos entre nome empresarial e marca e entre marcas, o tribunal: 
(2a) investigou o caráter de alto renome das partes envolvidas, com a conclusão de que ambas não têm tal status, visto não terem obtido tal reconhecimento quando do registro no INPI, para, posteriormente;

(2b) aferiu o caráter patronímico do termo "Odebrecht" em relação a ambas as sociedades empresárias; e

(2c) perquiriu a aplicabilidade do critério da especificidade, o qual é decisivo para a solução do problema, visto que as sociedades empresárias atuam em ramos de atividade distintos.

O caráter nitidamente tipológico do raciocínio desenvolvido pelo STJ ficou patente na combinação entre os seguintes argumentos:

1) o argumento de que, a despeito de o princípio da novidade ser, prima facie, um obstáculo à existência de homonímia, a composição total do nome é suficiente para evitar a confusão entre os consumidores, visto que os patronímicos idênticos foram acompanhados por termos que, em consonância com o princípio da veracidade, identificam os ramos de atividade contemplados pelas duas sociedades empresárias;

2) o argumento de que o princípio da novidade pode ser relativizado nas circunstâncias em que o elemento comum em conflitos nome/nome seja o patronímico dos fundadores da sociedade empresária;

3) o argumento teleológico de que o fato de a função primordial da proteção ao nome empresarial (individualizar a sociedade empresária no tocante às relações jurídicas em que está envolvida) ser diferente da função precípua da proteção à marca (distinguir o produto ou serviço em relação à concorrência) deve implicar uma diferença de rigidez do critério de avaliação da existência de confusão entre os consumidores em contextos distintos - o de conflitos nome/nome e o de conflitos que envolvem marcas - de modo a resultar na conclusão de que um conflito nome/marca não pode ser resolvido meramente pelo critério de anterioridade do registro; e 
4) o argumento sistemático de que os princípios referentes à disciplina marcária (territorialidade e especificidade) devem ser aplicados à tutela do nome empresarial, já que esta, na Lei 5772/71, figura como uma espécie de "intrusa"

Diante do exposto, percebe-se que tipos como novidade, veracidade, territorialidade e especificidade foram objeto de diversos deslocamentos de sentido em função da ponderação contextual de fatos realizada pelo STJ, em típica (!) manifestação do modelo de raciocínio jurídico descrito por Larenz. 


\section{REFERÊNCIAS}

BRASIL, Superior Tribunal de Justiça. EDcl nos EDcl no AgRg no RECURSO ESPECIAL No 653.609 - RJ. Rel: Min. Jorge Scartezzini. Disponível em: www.stj.gov.br. Acesso em: 30 de abr. 2020.

CERQUEIRA, João da Gama. Tratado da Propriedade Industrial. V. 2. São Paulo: Revista dos Tribunais, 1982, p. 1.230.

COELHO, Fabio Ulhoa. Curso de Direito Comercial. $23^{\text {a }}$ edição. São Paulo: Editora Saraiva, 2019.

DWORKIN, Ronald. Levando os direitos a sério. $2^{\text {a }}$ edição. São Paulo: Martins Fontes, 2002 .

HART, Herbert Lionel Adolphus. O conceito de Direito. Lisboa: Fundação Calouste Gulbenkian, 2001.

LARENZ, Karl. Metodologia da ciência do direito. Lisboa: Editora Calouste Gulbenkian, 2005.

MARTINS-COSTA, Judith. A boa-fé no direito privado: critérios para a sua aplicação. São Paulo: Marcial Pons, 2015.

MIGUEL, Daniel Oitaven Pamponet. Conflitos nome-nome, nome-marca e marca-marca: uma análise da decisão do STJ no "caso Odebrecht". Conteúdo Jurídico, Brasília-DF. Disponível em: https://www.conteudojuridico.com.br/consulta/Artigos/43110/conflitos-nomenome-nome-marca-e-marca-marca-uma-analise-da-decisao-do-stj-no-quot-caso-odebrechtquot . Acesso em: 03 mai. 2020.

SANTIAGO, Leonardo Ayres. Os institutos do nome e marca empresariais sob a ótica do caso Odebrecht. Revista Jus Navigandi, Teresina, ano 14, n. 2225. Disponível em: https://jus.com.br/artigos/13271. Acesso em: 3 mai. 2020.

SILVA, Rodney Malveira da. Hermenêutica jurídica contratual. São Paulo: Editora Atlas, 2011.

TOMAZETTE, Marlon. A proteção ao nome empresarial. Disponível em: <http://www.buscalegis.ufsc.br/arquivos/a310506_10.html>. Acesso em: 16 de janeiro de 2015.

VERAS, Adriene Maria de Miranda. Considerações sobre as figuras do nome comercial e da marca, da sua proteção e critérios de solução de conflitos à luz da jurisprudência do Superior Tribunal de Justiça. Âmbito Jurídico, n. 170, v. XXI, mar. 2018. Disponível em: https://ambitojuridico.com.br/revista-ambito-juridico/revista-ambito-juridico-no-170-ano-Xximarco-2018/. Acesso em: 03 mai. 2020. 